\title{
Front Matter: Volume 7698
}

, "Front Matter: Volume 7698," Proc. SPIE 7698, Signal and Data Processing of Small Targets 2010, 769801 (4 May 2010); doi: 10.1117/12.865613

SPIE Event: SPIE Defense, Security, and Sensing, 2010, Orlando, Florida, United SPIE. States 


\section{PROCEEDINGS OF SPIE}

\section{Signal and Data Processing of Small Targets 2010}

Oliver E. Drummond

Editor

5-8 April 2010

Orlando, Florida, United States

Sponsored and Published by

SPIE

Volume 7698

Proceedings of SPIE, 0277-786X, v. 7698 
The papers included in this volume were part of the technical conference cited on the cover and title page. Papers were selected and subject to review by the editors and conference program committee. Some conference presentations may not be available for publication. The papers published in these proceedings reflect the work and thoughts of the authors and are published herein as submitted. The publisher is not responsible for the validity of the information or for any outcomes resulting from reliance thereon.

Please use the following format to cite material from this book:

Author(s), "Title of Paper," in Signal and Data Processing of Small Targets 2010, edited by Oliver E. Drummond, Proceedings of SPIE Vol. 7698 (SPIE, Bellingham, WA, 2010) Article CID Number.

ISSN 0277-786X

ISBN 9780819481627

Published by

SPIE

P.O. Box 10, Bellingham, Washington 98227-0010 USA

Telephone +1 3606763290 (Pacific Time) · Fax +1 3606471445

SPIE.org

Copyright (c) 2010, Society of Photo-Optical Instrumentation Engineers

Copying of material in this book for internal or personal use, or for the internal or personal use of specific clients, beyond the fair use provisions granted by the U.S. Copyright Law is authorized by SPIE subject to payment of copying fees. The Transactional Reporting Service base fee for this volume is $\$ 18.00$ per article (or portion thereof), which should be paid directly to the Copyright Clearance Center (CCC), 222 Rosewood Drive, Danvers, MA 01923. Payment may also be made electronically through CCC Online at copyright.com. Other copying for republication, resale, advertising or promotion, or any form of systematic or multiple reproduction of any material in this book is prohibited except with permission in writing from the publisher. The CCC fee code is 0277-786X/10/\$18.00.

Printed in the United States of America.

Publication of record for individual papers is online in the SPIE Digital Library.

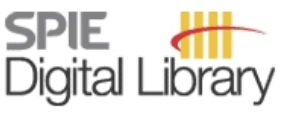

SPIEDigitalLibrary.org

Paper Numbering: Proceedings of SPIE follow an e-First publication model, with papers published first online and then in print and on CD-ROM. Papers are published as they are submitted and meet publication criteria. A unique, consistent, permanent citation identifier (CID) number is assigned to each article at the time of the first publication. Utilization of CIDs allows articles to be fully citable as soon they are published online, and connects the same identifier to all online, print, and electronic versions of the publication. SPIE uses a six-digit CID article numbering system in which:

- The first four digits correspond to the SPIE volume number.

- The last two digits indicate publication order within the volume using a Base 36 numbering system employing both numerals and letters. These two-number sets start with 00, 01, 02, 03, 04 , $05,06,07,08,09,0 A, 0 B \ldots$. OZ, followed by 10-1Z, 20-2Z, etc.

The CID number appears on each page of the manuscript. The complete citation is used on the first page, and an abbreviated version on subsequent pages. Numbers in the index correspond to the last two digits of the six-digit CID number. 


\section{Contents}

ix Conference Committee

xi Introduction

SESSION 1 SMALL TARGET SIGNAL PROCESSING

769802 A complex-domain adaptive order statistic filter and its application to signal detection in non-Gaussian noise and clutter [7698-01]

M. Fernández, T. Aridgides, Lockheed Martin (United States)

$769803 \quad$ Needle picking: a sampling based track-before-detection method for small targets [7698-02]

F. Porikli, Mitsubishi Electric Research Labs. (United States)

769804 Small moving targets detection using outlier detection algorithms [7698-03]

N. Reljin, S. McDaniel, D. Pokrajac, N. Pejcic, T. Vance, Delaware State Univ. (United States); A. Lazarevic, United Technologies Research Ctr. (United States); L. J. Latecki, Temple Univ. (United States)

769805 MIMO radar systems based on the generalized detector and space-time coding [7698-04] V. Tuzlukov, Kyungpook National Univ. (Korea, Republic of)

\section{SESSION 2 CHEMICAL/BIOLOGICAL PROCESSING}

769806 Algorithms for distributed chemical sensor fusion [7698-42]

S. Lundberg, R. Paffenroth, J. Yosinski, Numerica Corp. (United States)

769807 Identifying chemicals from their Raman spectra using minimum description length [7698-06] R. D. Palkki, A. D. Lanterman, Georgia Institute of Technology (United States)

769808 Wavelet-based denoising and baseline correction for enhancing chemical detection [7698-07]

R. M. Rao, U.S. Army Research Lab. (United States); M.-A. Slamani, T. H. Chyba, ITT Information Systems Div. (United States); D. K. Emge, U.S. Army Edgewood Chemical Biological Ctr. (United States)

$769809 \quad$ Nonlinear estimation for arrays of chemical sensors [7698-08] J. Yosinski, R. Paffenroth, Numerica Corp. (United States)

$76980 \mathrm{~A}$ Optimization of a chemical identification algorithm [7698-09]

T. H. Chyba, B. Fisk, C. Gunning, K. Farley, A. Polizzi, D. Baughman, S. Simpson, M.-A. Slamani, R. Almassy, R. Da Re, E. Li, S. MacDonald, A. Slamani, S. A. Mitchell, J. Pendell-Jones, ITT Corp. (United States); T. L. Reed, Engineering Consultant, Robust Design and Product Safety

(United States); D. Emge, U.S. Army Edgewood Chemical Biological Ctr. (United States) 
7698 OB Comparative studies of Raman spectra estimation algorithms for single and multiple chemical substances [7698-10]

M. Mallick, Georgia Tech Research Institute, Georgia Institute of Technology (United States)

$76980 \mathrm{C}$ Tracking interacting dust: comparison of tracking and state estimation techniques for dusty plasmas [7698-11]

N. P. Oxtoby, J. F. Ralph, D. Samsonov, C. Durniak, Univ. of Liverpool (United Kingdom)

\section{SESSION 3 FILTERING AND TRACK PROCESSING}

7698 OD Track segment association for ground moving targets with evasive move-stop-move maneuvers [7698-12]

S. Zhang, Y. Bar-Shalom, Univ. of Connecticut (United States)

7698 OE Temporal characterization of small arms muzzle flash in the broadband visible [7698-53] T. Burke, D. Bratlie, Northrop Grumman Corp. (United States)

7698 OF CPHD and PHD filters for unknown backgrounds, part III: tractable multitarget filtering in dynamic clutter [7698-14]

R. Mahler, Lockheed Martin MS2 (United States); A. El-Fallah, Scientific Systems Co., Inc. (United States)

7698 OG Distance and velocity estimation of projectiles based on Doppler radar signals using a nonlinear discrete-time observer [7698-15]

S. Podjawerschek, E. Spahn, Institute of Saint-Louis (France); J. Horn, Helmut-Schmidt-Univ. (Germany); M. Brodmann, Univ. of Applied Sciences Gelsenkirchen (Germany);

R. Himmelsbach, Institute of Saint-Louis (France)

$7698 \mathrm{OH} \quad$ Spline filter for target tracking [7698-16]

D. L. Kocherry, R. Tharmarasa, McMaster Univ. (Canada); T. Lang, General Dynamics

Canada (Canada); T. Kirubarajan, McMaster Univ. (Canada)

7698 ol Generalized particle flow for nonlinear filters [7698-17]

F. Daum, J. Huang, Raytheon Co. (United States)

7698 0J The GM-CPHD applied to the corrected TNO-Blind, adjusted SEABAR07 and Metron multi-static sonar datasets [7698-43]

R. Georgescu, P. Willett, Univ. of Connecticut (United States)

\section{SESSION 4 TARGET TRACK PROCESSING}

7698 OK Maximum likelihood probabilistic data association tracker applied to bistatic sonar data sets [7698-19]

S. Schoenecker, Naval Undersea Warfare Ctr. (United States); P. Willett, Y. Bar-Shalom, Univ. of Connecticut (United States)

$7698 \mathrm{OL}$ Probabilistic data association in high clutter environments [7698-20]

R. Tharmarasa, McMaster Univ. (Canada); T. Lang, General Dynamics Canada (Canada); M. McDonald, Defence Research and Development Canada (Canada); T. Kirubarajan, McMaster Univ. (Canada) 
7698 OM Association ambiguity management in mixed data dimension tracking problems [7698-21] J. R. Thornbrue, J. N. Knight, B. J. Slocumb, Numerica Corp. (United States)

7698 ON A tracker adjunct processing system for reconsideration of firm tracker decisions [7698-44] D. J. Trawick, B. J. Slocumb, R. C. Paffenroth, Numerica Corp. (United States)

$769800 \quad$ Two-level automatic multiple target joint tracking and classification [7698-23]

X. He, R. Tharmarasa, McMaster Univ. (Canada); M. Pelletier, ICx Radar System (Canada);

T. Kirubarajan, McMaster Univ. (Canada)

7698 OP Using PMHT for separation point estimation [7698-24]

D. T. Dunham, S. E. August, Vectraxx, Inc. (United States)

$7698 \mathrm{OQ} \quad 3 \mathrm{D}$ target modeling and activity analysis through target tracking [7698-25]

K. Salva, S. Bischoff, J. R. Vasquez, Numerica Corp. (United States)

7698 OR State estimation performance of tracking system with range rate measurements [7698-26]

Y. Zhu, H. Fan, L. Hu, Q. Fu, National Univ. of Defense Technology (China)

\section{SESSION 5 SENSOR DATA FUSION PROCESSING}

7698 OS A no-loss covariance intersection algorithm for track-to-track fusion [7698-27] $X$. Tian, DCM Research Resources LLC (United States) and Univ. of Connecticut (United States); Y. Bar-Shalom, Univ. of Connecticut (United States); G. Chen, DCM Research Resources LLC (United States)

7698 ОT Covariance consistency for track initiation using Gauss-Hermite quadrature [7698-28] J. T. Horwood, N. D. Aragon, A. B. Poore, Numerica Corp. (United States)

7698 OU Scalable self-organizing resource management for multi-function radars in a sensor network [7698-29]

B. S. Weir, T. M. Sokol, Johns Hopkins Univ. (United States)

$76980 \mathrm{~V}$ Information-based awareness model and active sensing in sensor resource management [7698-30]

D. Shen, DCM Research Resources LLC (United States); Z. Tian, Michigan Technological Univ. (United States); G. Chen, DCM Research Resources LLC (United States); K. Pham, E. Blasch, Air Force Research Lab. (United States)

7698 0W The optimal algorithm for asynchronous track-to-track fusion [7698-46] $X$. Tian, Y. Bar-Shalom, Univ. of Connecticut (United States)

7698 0X Network-centric angle only tracking using rank-deficient filtering [7698-32]

N. Coult, J. N. Knight, Numerica Corp. (United States)

7698 OY Multitarget sensor resolution model for arbitrary target numbers [7698-33]

D. Svensson, Chalmers Univ. of Technology (Sweden); M. Ulmke, Fraunhofer-FKIE (Germany);

L. Danielsson, Volvo Car Corp. (Sweden) 
769810 Adaptive tracking in sensor data fusion [7698-35]

O. E. Drummond, CyberRnD, Inc. (United States)

769811 Unified sensor management in unknown dynamic clutter [7698-36]

R. Mahler, Lockheed Martin MS2 (United States); A. El-Fallah, Scientific Systems Co., Inc. (United States)

769812 Probabilistic tracking of multiple extended targets using random matrices [7698-37] M. Wieneke, W. Koch, Fraunhofer-FKIE (Germany)

769813 The JPDAF in practical systems: computation and snake oil [7698-38]

D. F. Crouse, Y. Bar-Shalom, P. Willett, Univ. of Connecticut (United States); L. Svensson, Chalmers Univ. of Technology (Sweden)

769814 An assignment based distributed resource manager [7698-39]

A. B. Poore, S. Danford, M. J. Hilt, Numerica Corp. (United States)

769815 Integration of passive ranging with multiple hypothesis tracking (MHT) for application with angle-only measurements [7698-40]

S. Blackman, T. White, B. Blyth, C. Durand, Raytheon Co. (United States)

$769816 \quad$ Numerical experiments for nonlinear filters with exact particle flow induced by log-homotopy [7698-41]

F. Daum, J. Huang, Raytheon Co. (United States)

\section{SESSION 7 SIGNAL AND DATA PROCESSING}

769817 Comparison of swarm intelligence optimization with nonnegative weighted least squares for Raman spectra estimation [7698-05]

N. Srinivas, Syracuse Univ. (United States); M. Mallick, Georgia Tech Research Institute (United States); L. A. Osadciw, Syracuse Univ. (United States)

769818 On-road obstacle detection and tracking system using robust global stereo vision method [7698-45]

S. Kwon, J.-H. Lee, Daegu Gyeongbuk Institute of Science \& Technology (Korea, Republic of); I. Na, H. Jung, Pohang Univ. of Science and Technology (Korea, Republic of)

$76981 \mathrm{~A} \quad$ Multipath-assisted multitarget tracking with reflection point uncertainty [7698-48] M. Subramaniam, R. Tharmarasa, McMaster Univ. (Canada); M. McDonald, Defence Research and Development Canada (Canada); T. Kirubarajan, McMaster Univ. (Canada)

7698 1B Wide-area feature-aided tracking with intermittent multi-sensor data [7698-49] C. Carthel, S. Coraluppi, K. Bryan, G. Arcieri, NATO Undersea Research Ctr. (Italy)

7698 1C Synthetic aperture radar imaging in the cross-range [7698-50]

J. X. Lopez, G. Garza, Z. Qiao, The Univ. of Texas-Pan American (United States) 
7698 1D A survey of maneuvering target tracking, part Vla: density-based exact nonlinear filtering [7698-51]

X. R. Li, V. P. Jilkov, Univ. of New Orleans (United States)

7698 1E A survey of maneuvering target tracking, part VIb: approximate nonlinear density filtering in mixed time [7698-52]

X. R. Li, V. P. Jilkov, Univ. of New Orleans (United States)

$76981 \mathrm{G}$ Impact point prediction for short range thrusting projectiles [7698-55]

T. Yuan, Y. Bar-Shalom, P. Willett, Univ. of Connecticut (United States); D. Hardiman, AMRDEC (United States)

$7698 \mathrm{1H} \quad$ Aided strapdown inertial navigation for autonomous underwater vehicles [7698-56]

Y. Liu, X. R. Li, The Univ. of New Orleans (United States)

769811 The JPDAF in practical systems: approximations [7698-57]

K. Romeo, D. F. Crouse, Y. Bar-Shalom, P. Willett, Univ. of Connecticut (United States)

Author Index 
Downloaded From: https://www.spiedigitallibrary.org/conference-proceedings-of-spie on 26 Apr 2023

Terms of Use: https://www.spiedigitallibrary.org/terms-of-use 


\title{
Conference Committee
}

\author{
Symposium Chair
}

Michael T. Eismann, Air Force Research Laboratory (United States)

Symposium Cochair

William Jeffrey, HRL Laboratories, LLC (United States)

Conference Chair

Oliver E. Drummond, Consulting Engineer (United States)

Conference Cochair

Richard D. Teichgraeber, Consulting Engineer (United States)

Program Committee

Liyi Dai, U.S. Army Research Office (United States)

Darren K. Emge, U.S. Army Edgewood Chemical Biological Center (United States)

Lawrence E. Hoff, Hoff Engineering (United States)

Denise E. Jones, U.S. Army Space and Missile Defense Command (United States)

Rabinder N. Madan, Office of Naval Research (United States)

Steven W. Waugh, Defense Threat Reduction Agency (United States)

Session Chairs

$1 \quad$ Small Target Signal Processing

Darren Emge, U.S. Army Edgewood Chemical Biological Center (United States)

Oliver E. Drummond, Consulting Engineer (United States)

2 Chemical/Biological Processing

Steven W. Waugh, Defense Threat Reduction Agency (United States)

Darren Emge, U.S. Army Edgewood Chemical Biological Center (United States)

$3 \quad$ Filtering and Track Processing

Liyi Dai, U.S. Army Research Office (United States)

Richard D. Teichgraeber, Consulting Engineer (United States) 
$4 \quad$ Target Track Processing

Richard D. Teichgraeber, Consulting Engineer (United States)

Oliver E. Drummond, Consulting Engineer (United States)

$5 \quad$ Sensor Data Fusion Processing

Rabinder N. Madan, Office of Naval Research (United States)

Liyi Dai, U.S. Army Research Office (United States)

6 Track and Sensor Data Fusion Processing

Oliver E. Drummond, Consulting Engineer (United States)

Denise E. Jones, U. S. Army Space and Missile Defense Command (United States)

$7 \quad$ Signal and Data Processing

Richard D. Teichgraeber, Consulting Engineer (United States)

Oliver E. Drummond, Consulting Engineer (United States) 


\section{Introduction}

This was the $22^{\text {nd }}$ in a series of SPIE conferences to focus on signal and data processing of small targets. Most SPIE conferences are concerned with processing large targets, namely, targets large enough for traditional automatic (or assisted) target recognition (ATR) with a single frame of data. A target large enough for ATR is typically larger than a total of 100 resolution elements, for example, larger than 10 by 10 pixels. In contrast, this conference series introduced a different thrust for SPIE: processing targets smaller than 100 pixels.

This year the conference was held in Orlando after being held in San Diego the prior year. In the future, these conferences are expected to be located in Baltimore in the spring on even years but continue to be in San Diego in the summer on odd years. The proceedings of the prior conferences in this series in 1989 through 2009 are SPIE Volumes 1096, 1305, 1481, 1698, 1954, 2235, 2561, 2759 , $3163,3373,3809,4048,4473,4728,5204,5428,5913,6236,6699,6969$, and 7445. A compact disk of all the papers in this series from 1989 through 2000 is available from SPIE; it is Volume 20, which is a two-disk set.

The various types of processing tasks with sensor-derived data of targets can be broadly categorized into four generic classes, as follows:

- Sensor tracking of a single (bright) target

- Image and data processing of large targets

- Signal and data processing of medium sized targets

- Signal and data processing of small targets.

Note that the size indicated in this list is in terms of the number of resolution elements or pixels. The motivation for categorizing the processing of sensor data this way is because most of the appropriate algorithms for each of these problems differ substantially from that of the others. This conference concentrates on small targets that include:

- Point source objects

- Small extended objects

- Clusters of point source and small extended objects or a threat cloud, such as a Bio/Chem threat.

The size of a typical point source target in the field of view is from less than one to about 20 pixels (resolution elements) wide, depending on the sensor design. Although the processing of point targets with data form a single sensor has been 
studied extensively, there are still many interesting challenges in this field. In contrast, the state of the art of sensor data fusion and for processing small extended-objects and clusters is far less mature, but interest is growing.

Small targets that are not point source objects include both small extended objects and unresolved closely spaced objects, sometimes called clumps. While these small targets provide little detailed information useful for ATR, they do exhibit some shape and size information that might be useful in tracking. In addition, an extended object may at times be partially or fully obscured or may obscure rather than add to the background. The apparent size and shape of a target can differ from sensor-to-sensor and over time; this may have to be taken into account. Similarly, cluster processing offers significant advantages and challenges.

Improved sensors, increasingly demanding system requirements, processor hardware limitations, severe operating environments, efficacious countermeasures, and challenging threat scenarios, drive current algorithm development. Of special interest is the ability to track low observables or in a moderate to dense population of threshold exceedances caused by clutter, false signals, or targets that are close or crossing.

There is an increasing need for improvements in "algorithm efficiency," i.e., improved performance relative to the processor and communication resources required. A major trade in selecting algorithms for processing small targets is performance versus required processor and communications capacity. Also needed are accurate evaluations and predictions of required resources and functional performance under realistic conditions. Major improvements are needed in: multiple spectral signal processing, multiple target tracking, network centric sensor data fusion, multiple frame data association, multiple frame signal processing (such as track-before-detect), effective management of sensors, communications, and processor resources, target classification, processing of features and attributes, and the interaction between signal processing and tracking. Many of these issues are highlighted in Figure 1. In addition, there is a need for an indication of track quality and related information in the tracker output to the users and functions that depend on the tracker data to facilitate the improvement of their performance.

The term fuse-before-detect in Figure 1 refers to the combining (fusing) of raw data from multiple sensors before applying a threshold (detection) at the signal processing level. I coined this term in recognition of the increased interest in improving performance by fusing sensor data early in the processing chain. Note also in Figure 1 the possible use of track data at the signal processing level. There is a growing recognition of the importance of using all available information in every stage of the processing and hence the use of feedback. 


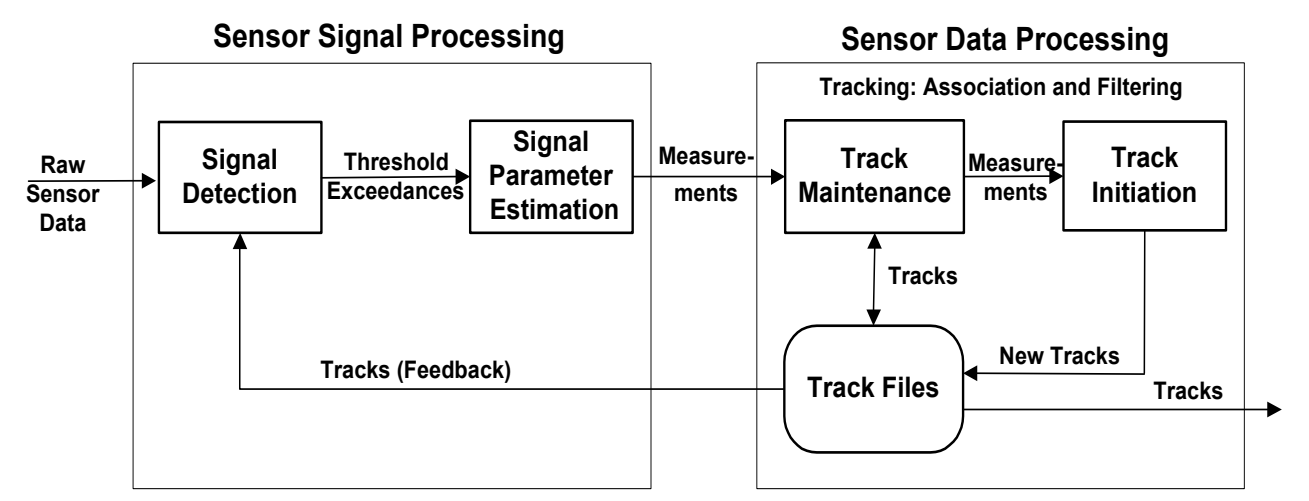

- Single-Frame Signal Processing

- Multiple-Frame Signal Processing

- Fuse Before Detect
- Single-Frame Association

- Multiple-Frame Association

- Multiple-Sensor Processing

\section{Figure 1. Sensor Signal and Data Processing}

This conference has provided a forum to address these issues through discussion of algorithms and simulations for both digital signal processing and target tracking under challenging conditions, i.e., association (correlation) and filtering, including related data processing, such as sensor fusion, resource management, and target classification/typing. Of the six half-day sessions, one addressed signallevel processing, one concentrated on chemical/biological processing, and three addressed target tracking and its functions, and two addressed sensor data fusion and related network wide processing. The distinction between the two stages of single sensor-level processing is shown in Figure 1.

These proceedings papers contain a wealth of information that address the issues critical to practical processing under the challenging conditions outlined above. For example, important advances were presented in: processing chemical sensor data, particle filter methods to accommodate non-linearities, multiple hypothesis tracking, advanced distributed sensor data fusion, network-level resource management, tracking with passive sensors, tracking ground targets, track quality, projectile tracking, and adaptive track processing. These techniques and others presented are strong candidates to permit high performance target tracking and sensor data fusion and related processing of low observables or in an environment of moderately dense detections and with abruptly maneuvering targets. These and other innovative yet practical techniques were presented that contribute to improving algorithm efficiency for processing small targets. 
Many of the experts and organizations that are making the major important advances in practical sensor signal and data processing have contributed to these proceedings. We thank the authors, session chairs, attendees, and SPIE coordinators for making the three-day conference such a success. They have taken part in enthusiastic discussions that generated better understanding for the application of the techniques presented and have stimulated thoughts for further improvements. Informal discussions during the coffee breaks and the poster session were especially productive, as usual. With these proceedings, the authors have extended the state of the art of analysis, algorithms, and simulations for the use of data from one or more sensors used in signal and data processing of small targets and related processing.

Oliver E. Drummond, Ph.D., P.E.

Consulting Engineer

Phone: $310-838-5300$

E-Mail: Drummond@Att.Net

Web site: http://ODrummond.com 